Article

\title{
GeTe-TiC-C Composite Anodes for Li-Ion Storage
}

\author{
Woo Seob Kim, Thuan Ngoc Vo and Il Tae Kim * \\ Department of Chemical and Biological Engineering, Gachon University, Seongnam-si, Gyeonggi-do 13120, \\ Korea; termies@naver.com (W.S.K.); vnthuanbk@gmail.com (T.N.V.) \\ * Correspondence: itkim@gachon.ac.kr; Tel.: +82-31-750-8835; Fax: +82-31-750-5363
}

Received: 14 August 2020; Accepted: 19 September 2020; Published: 23 September 2020

\begin{abstract}
Germanium boasts a high charge capacity, but it has detrimental effects on battery cycling life, owing to the significant volume expansion that it incurs after repeated recharging. Therefore, the fabrication of Ge composites including other elements is essential to overcome this hurdle. Herein, highly conductive Te is employed to prepare an alloy of germanium telluride (GeTe) with the addition of a highly conductive matrix comprising titanium carbide $(\mathrm{TiC})$ and carbon $(\mathrm{C})$ via high-energy ball milling (HEBM). The final alloy composite, GeTe-TiC-C, is used as a potential anode for lithium-ion cells. The GeTe-TiC-C composites having different combinations of $\mathrm{TiC}$ are characterized by electron microscopies and X-ray powder diffraction for structural and morphological analyses, which indicate that $\mathrm{GeTe}$ and $\mathrm{TiC}$ are evenly spread out in the carbon matrix. The GeTe electrode exhibits an unstable cycling life; however, the addition of higher amounts of $\mathrm{TiC}$ in $\mathrm{GeTe}$ offers much better electrochemical performance. Specifically, the GeTe-TiC (20\%)-C and GeTe-TiC (30\%)-C electrodes exhibited excellent reversible cyclability equivalent to 847 and $614 \mathrm{mAh} \mathrm{g}^{-1}$ after 400 cycles, respectively. Moreover, at $10 \mathrm{~A} \mathrm{~g}^{-1}$, stable capacity retentions of $78 \%$ for GeTe-TiC (20\%)-C and $82 \%$ for GeTe-TiC (30\%)-C were demonstrated. This proves that the developed GeTe-TiC-C anodes are promising for potential applications as anode candidates for high-performance lithium-ion batteries.
\end{abstract}

Keywords: germanium telluride; titanium carbide; conductive matrix; anodes; lithium-ion batteries

\section{Introduction}

In recent times, the number of customers interested in purchasing electric vehicles and electronic devices is steadily increasing, and these products demand long-lasting energy storage systems. Thus, the energy storage market has continuously and significantly grown over the past decades; specifically, batteries and battery-related technologies have become increasingly vital for modern technology [1-3]. Lithium-ion batteries (LIBs) have been commonly utilized globally as energy storage systems. Owing to the desirability of long-lasting operation with one charge, the demand for LIBs with higher energy density and more stable performance is steadily increasing. To date, graphite anodes have been applied in LIBs; however, they exhibit a low theoretical capacity $\left(\approx 372 \mathrm{mAh} \mathrm{g}^{-1}\right)$, low tap density $\left(<1 \mathrm{~g} \mathrm{~cm}^{-3}\right)$, and low energy density. Further, safety issues and performance degradation related to Li plating on the graphite surface remain unresolved, which has encouraged the exploration of new anode materials [4-8]. To address the aforementioned disadvantages, various Li-alloying elements such as $\mathrm{Sb}, \mathrm{Sn}, \mathrm{Si}$, and $\mathrm{Ge}$ have been proposed as potential anode materials for replacing graphite [9-16]. Ge exhibits a higher theoretical capacity $\left(1385 \mathrm{mAh} \mathrm{g}^{-1}\right)$ than that $\left(\approx 372 \mathrm{mAh} \mathrm{g}^{-1}\right)$ of graphite, an electrical conductivity $\left(2.1 \mathrm{~S} \mathrm{~m}^{-1}\right)[10,17,18]$ higher than $\mathrm{Si}\left(1.6 \times 10^{-3} \mathrm{~S} \mathrm{~m}^{-1}\right)$, and a lithium diffusivity 400 times faster than Si [19-22]. Despite these advantages, Ge anodes face a major disadvantage pertaining to poor cycling because of the $300 \%$ volume variation during repeated electrochemical process [23,24]. In this regard, effectual strategies are needed to provide structural stability for the composites by generating effective buffer phases and preventing nanoparticle agglomerations $[8,23-30]$. 
Among these, titanium carbide ( $\mathrm{TiC}$ ) could be used to fabricate an outstanding structural barrier, with its high conductivity and hardness [31,32]. Due to the specific properties of TiC, various studies on the electrodes with $\mathrm{TiC}$ and/or $\mathrm{C}$ have been explored, where the addition of $\mathrm{TiC}$ to the composite electrodes made it possible to show stable cyclic performances [23,33-37]. In addition, conductive carbon can enhance nanoparticle separation and the conductivity of composites, and it can also stabilize electrochemical performances for LIBs [24,28,38]. Meanwhile, for reducing the large volume expansion of the metallic $\mathrm{Ge}$, intermetallic components that act as a buffering step could be incorporated into composite electrodes. For this purpose, the chalcogens of sulfur (S), selenium (Se), and tellurium (Te) are potential candidates and can be alloyed with $\mathrm{Li}$ upon the $\mathrm{Li}_{2} \mathrm{X}(\mathrm{X}=\mathrm{S}, \mathrm{Se}, \mathrm{Te})$ phase formation [39-50]. Among them, Te has a reasonable theoretical capacity $\left(420 \mathrm{mAh} \mathrm{g}^{-1}\right)$ with a high conductivity (2.0 S $\mathrm{cm}^{-1}$ ). Moreover, Te reacts with $\mathrm{Li}$ ions at around 0.9-1.9 $\mathrm{V}$ to form $\mathrm{Li}_{2} \mathrm{Te}[35,46,48-51]$. Meanwhile, Ge has a different reaction potential $\left(\approx 0.6 \mathrm{~V}\right.$ vs. $\left.\mathrm{Li} / \mathrm{Li}^{+}\right)$; thus, $\mathrm{Ge}$ and Te react independently with lithium ions at separate potentials. Thus, it is expected that the formation of intermetallic germanium telluride $(\mathrm{GeTe})$ complexes in composites will effectively diminish significant volume variations upon cycling, owing to the possession of different redox potentials with $\mathrm{Li}$, leading to good electrochemical performance. In this study, based on the aforementioned scenario, the following strategies were chosen to obtain outstanding electrochemical performance. (1) Hybrid TiC and C matrices were developed. They led to an increase in conductivity, which generated the buffering effect, accommodated the volume change during cycles, and facilitated electron transport as well as $\mathrm{Li}$ ion diffusion. (2) The existence of Te with Ge suppressed the abrupt volume change. Based on these strategies, the fabricated GeTe-TiC-C composite electrode is expected to demonstrate superior electrochemical performance.

\section{Experimental}

\subsection{Preparation of GeTe and GeTe-TiC-C}

To synthesize GeTe and GeTe-TiC-C nanocomposites, a 1:1 molar ratio of Ge $(99.999 \%$, 100 mesh, Alfa Asear, Black freer, MA, USA) and Te (99.99\%, 100 mesh, Aldrich, St. Louis, MO, USA) were mixed, which were sealed in an Ar-filled glove box and high-energetically milled (Pulverisette 5, Fritsch, Markt Einersheim, Germany), with a powder: $\mathrm{ZrO}_{2}$ ball ratio of 1:20 for $24 \mathrm{~h}$ at a speed of 300 rpm. Similarly, acetylene black (99.9\%, Alfa Asear) and Ti (99.99\%, 325 mesh, Alfa Aesar) were mixed with a molar ratio of 1:1 and high-energetically milled for $24 \mathrm{~h}$ in the same condition, thus forming the $\mathrm{TiC}$ phase. Subsequently, the synthesized $\mathrm{GeTe}$ and $\mathrm{TiC}$ were mixed with acetylene black and prepared with different wt \% ratios (GeTe:TiC:C $=70: 10: 20,60: 20: 20$, and 50:30:20) in a container sealed with Ar gas. The prepared powder mixtures were milled again for $24 \mathrm{~h}$ at $300 \mathrm{rpm}$, which generated the final product-GeTe-TiC-C composites. The entire synthesis procedure is depicted in Figure 1.

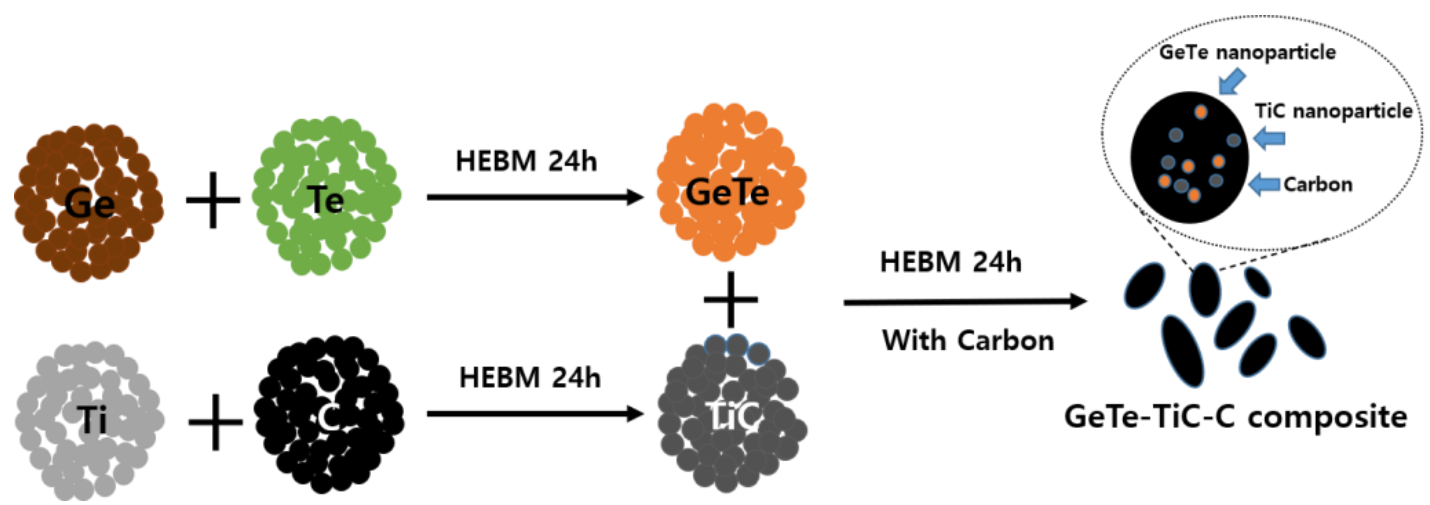

Figure 1. Schematic for the formation of GeTe-TiC-C composite. 


\subsection{Material Characterization}

The structure analysis of the as-synthesized powder materials was performed in the $2 \theta$ range of $20^{\circ}-60^{\circ}$ at a scan speed of $2^{\circ} \mathrm{min}^{-1}$ using X-ray diffraction (XRD) (D/MAX-2200, Rigaku, Tokyo, Japan) with the software of Smartlab studio 2 at the Smart Materials Research Center for IoT in Gachon University (v4.3.177.0, Tokyo, Japan). Scanning electron microscopy (SEM, Hitachi S-4700, Tokyo, Japan) was utilized in order to examine the morphology of GeTe and GeTe-TiC-C. High-resolution transmission electron microscopy (HRTEM, JEOL 2100, Tokyo, Japan) furnished with energy-dispersive X-ray spectroscopy (EDS) was used for analyzing the forms and compositions of the elements. For obtaining tap density with the unit of $\mathrm{g} \mathrm{cm}^{-3}$, the active material was put into a small measuring cylinder $(10 \mathrm{~mL})$ and tapped for $10 \mathrm{~min}$ so that the active material was packed well. Then, the weight of the active material was measured from the difference in weight between the empty measuring cylinder and the one occupied with active material. After measuring the volume of the active material, the tap density was calculated from the obtained volume and weight.

\subsection{The Measurement of the Electrochemical Properties}

To investigate the electrochemical properties, $70 \mathrm{wt} \%$ active materials (GeTe or GeTe-TiC-C powder), 15 wt \% Super P (conductive carbon black), and $15 \mathrm{wt} \%$ poly acrylic acid were homogenized thoroughly in an ethyl alcohol solution and cast in slurry on a flexible copper foil. After casting, they were dried overnight at $70{ }^{\circ} \mathrm{C}$ under vacuum condition. The electrodes were punched into a circular shape with a diameter of $12.5 \mathrm{~mm}$; moreover, they possessed 1-1.5 $\mathrm{mg}$ of GeTe or GeTe-TiC-C material. The CR2032-type half-cell was fabricated with $1 \mathrm{M} \mathrm{LiPF}_{6}$ in ethylene carbonate (EC) and diethyl carbonate (DEC) $(1: 1 \mathrm{v} / \mathrm{v})$ for use as the electrolyte; the working electrode consisted of GeTe or GeTe-TiC-C, and the counter electrode comprised of Li foil. The galvanostatic tests (WBCS300, WonAtech, Seoul, Korea) were conducted at a current density of $100 \mathrm{~mA} \mathrm{~g}^{-1}$ at $25^{\circ} \mathrm{C}$, and a fast-charging-performance test was performed at various current rates of $0.1,0.5,1,3,5$, and $10 \mathrm{~A} \mathrm{~g}^{-1}$ by considering the weight of the electroactive materials (GeTe or GeTe-TiC-C). Cyclic voltammetry (CV) as well as electrochemical impedance spectroscopy (EIS) analyses were performed using the ZIVE MP1 (WonAtech). The cyclic voltammograms were obtained in the potential range of $0.001-2.5 \mathrm{~V}$ versus $\mathrm{Li} / \mathrm{Li}^{+}$, with a scan rate of $0.1 \mathrm{mV} \mathrm{s}^{-1}$, and EIS data were obtained by applying an amplitude of $5 \mathrm{mV}$ over the frequency range of $100 \mathrm{kHz}-100 \mathrm{mHz}$ after the 100 th cycle.

\section{Results and Discussion}

The GeTe and GeTe-TiC-C powder samples are evaluated by XRD, and Figure 2 shows the XRD peaks of the as-prepared composites. To develop the targeted sample (GeTe-TiC-C), Ge/Te, and Ti/C were mechanically milled. Then, acetylene black was added with a fixed weight percent (20\%). The XRD peaks corresponding to GeTe (PDF \#47-1079) and TiC (PDF \#32-1383) coincided well with the reference peaks. The analysis of the GeTe-TiC-C composites with different weight percentages of $\mathrm{TiC}$ leads to the observation that when the $\mathrm{TiC}$ ratio increases, the intensity of the $\mathrm{TiC}$ peak increases, whereas a decrease in the GeTe peaks is observed.

The morphologies of GeTe-TiC (20\%)-C samples are shown in Figure 3. From the SEM and TEM images (Figure 3a,b), it is observed that irregular-shaped micro/nanoparticles were aggregated. Moreover, well-defined crystalline structures of GeTe and $\mathrm{TiC}$ were detected as evident from the high-resolution morphology images in Figure 3c, where interlayer spacing of $0.299 \mathrm{~nm}$ for GeTe (202) and $0.216 \mathrm{~nm}$ for TiC (200) crystalline phases were observed. The selected-area electron diffraction patterns also displayed several spots corresponding to the crystalline natures from GeTe and TiC. The amorphous regions could be designated as a part of the carbon matrix. Finally, the EDS-mapped images illustrate that each component including $\mathrm{Ge}, \mathrm{Te}, \mathrm{Ti}$, and $\mathrm{C}$ are well-dispersed in the composite. 


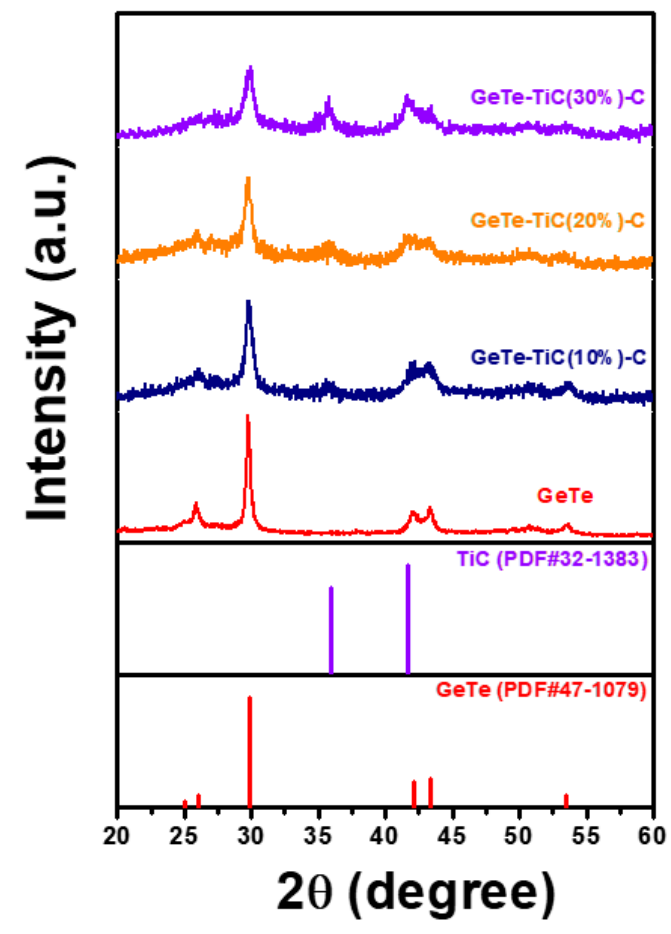

Figure 2. X-ray diffraction (XRD) patterns of GeTe and GeTe-TiC-C composites.

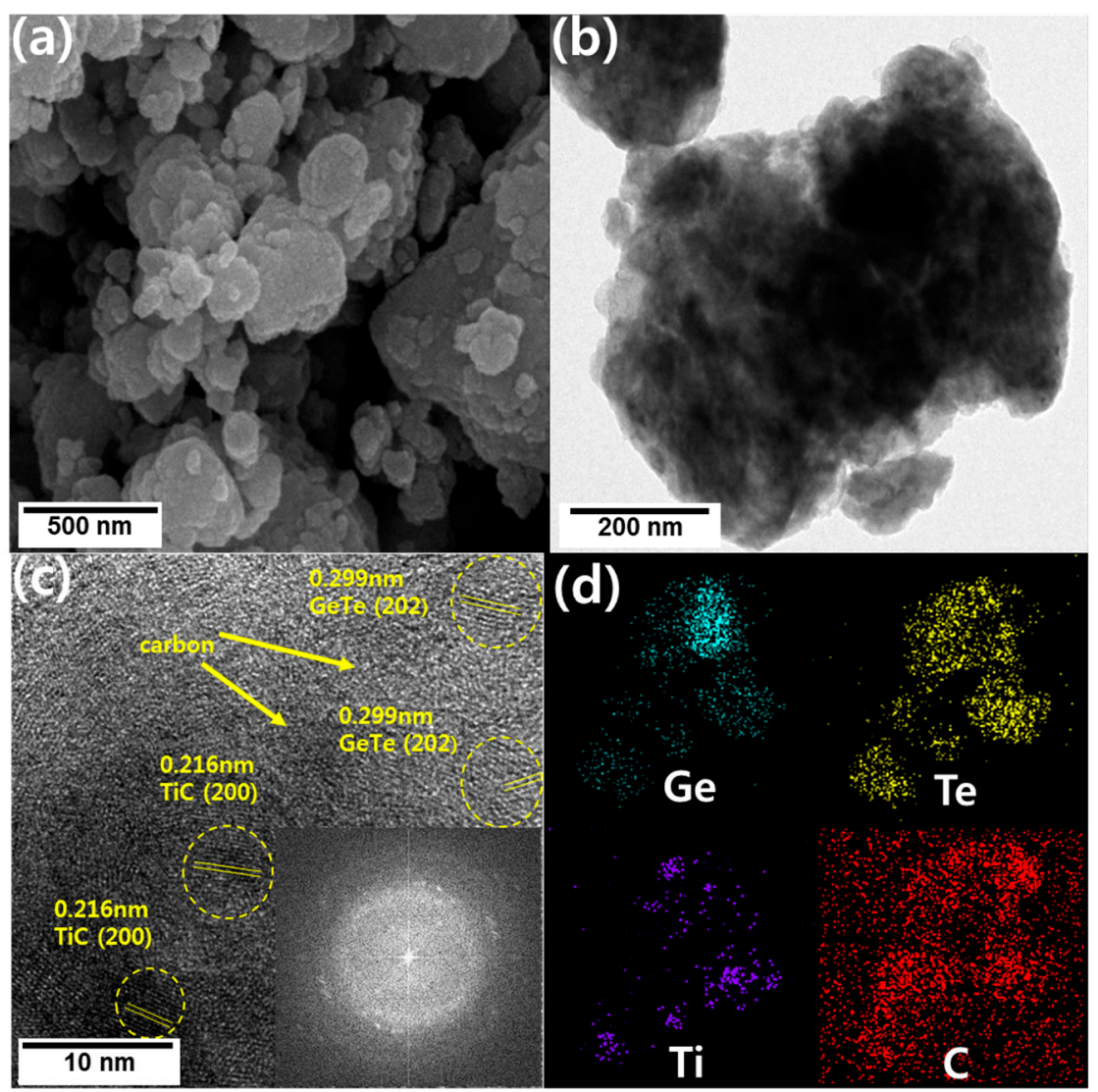

Figure 3. (a) Scanning electron microscopy (SEM), (b) Transmission electron microscopy (TEM), and (c) high-resolution TEM images of GeTe-TiC (20\%)-C. (d) Energy-dispersive X-ray spectroscopy (EDS) mapping images of GeTe-TiC (20\%)-C from Scanning transmission electron microscopy (STEM). 
The initial potential profiles of the as-prepared GeTe and GeTe-TiC-C composite electrodes were analyzed at $100 \mathrm{~mA} \mathrm{~g}^{-1}$, as shown in Figure 4. Additionally, the corresponding electrochemical data are summarized in Table 1. During the first discharge and charge cycle of the GeTe-TiC (10\%)-C, GeTe-TiC (20\%)-C, and GeTe-TiC (30\%)-C electrodes, a sloping plateau region appears at approximately $0.25 \mathrm{~V}$, which is attributed to the electrochemical reaction between $\mathrm{Ge}$ and Li ions. Furthermore, the other sloping plateau can be detected from 1.6 to $0.9 \mathrm{~V}$, corresponding to the electrochemical reaction between Te and Li ions. GeTe-TiC-C composites displayed sloping plateaus, unlike GeTe. This is because the crystalline nature starts disappearing, owing to the high TiC content [37,52]. The diffusion of Li ions is prevented in the 1st cycle, resulting in more side reactions and the development of the solid electrolyte interface (SEI) layer. Meanwhile, regarding the electrochemical initial performance, during the first cycle of the GeTe electrode, the discharge and charge capacities were 987 and $679 \mathrm{mAh}^{-1}$, respectively. The initial capacity loss is usually attributed to the development of SEI layers on the electrode surface. In this case, GeTe electrode displayed exceedingly poor electrochemical performances, with a considerably low initial Coulombic efficiency of $69 \%$. This inferior performance can be attributed to the absence of $\mathrm{TiC}$ and carbon, which acted as the buffering agent. In contrast, the composite anodes with the presence of $\mathrm{TiC}$ and $\mathrm{C}$ exhibited significantly better initial performance. Specifically, during the first cycle, the charge and discharge values of the GeTe-TiC-C electrodes respectively were 655 and $778 \mathrm{mAh}^{-1}$ for GeTe-TiC (10\%)-C, 558 and $729 \mathrm{mAh} \mathrm{g}^{-1}$ for GeTe-TiC (20\%)-C, and 508 and $722 \mathrm{mAh} \mathrm{g}^{-1}$ for GeTe-TiC (30\%)-C electrodes, where their initial Coulombic efficiencies were higher than that of the GeTe electrode (refer Table 1). Additionally, the increase in the TiC content reduced the initial charge capacity, resulting from the low activity of $\mathrm{TiC}$ with Li ions. Furthermore, the initial Coulombic efficiency also decreased with an increase in $\mathrm{TiC}$ content. Although $\mathrm{TiC}$ could significantly improve the stability of the composite electrodes, it was found that an excess amount of TiC frequently caused a decline in the initial Coulombic efficiency [35,53]. Nevertheless, after long cycling, the electrodes with TiC content exhibited outstanding capacity retentions (discussed later).

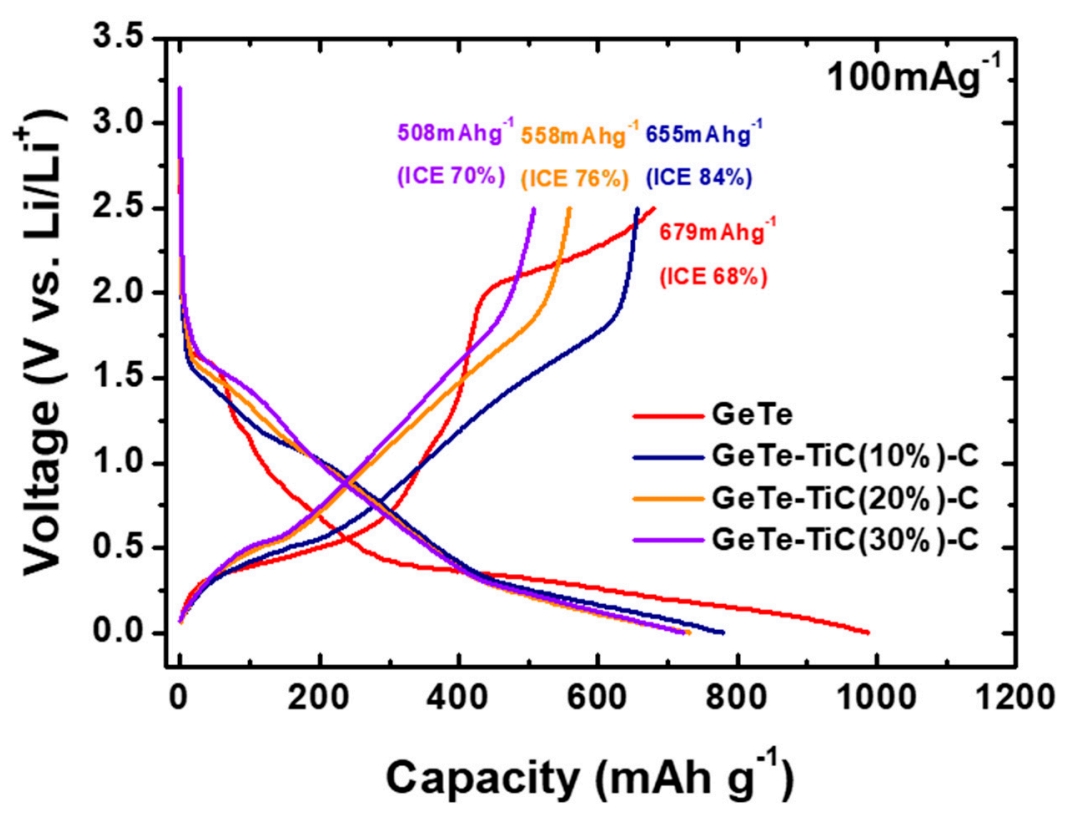

Figure 4. Initial voltage profiles of GeTe and GeTe-TiC-C (TiC: 10, 20 and 30 wt \%) electrodes at a constant current density of $100 \mathrm{~mA} \mathrm{~g}^{-1}$. 
Table 1. Electrochemical properties of GeTe and GeTe-TiC-C electrodes.

\begin{tabular}{|c|c|c|c|c|}
\hline Sample & $\begin{array}{l}\text { 1st Charge } \\
\text { Capacity } \\
\left(\mathrm{mAh} \mathrm{g}^{-1}\right)\end{array}$ & $\begin{array}{l}\text { 1st Discharge } \\
\text { Capacity } \\
\left(\mathrm{mAh} \mathrm{g}^{-1}\right)\end{array}$ & $\begin{array}{l}\text { Initial Coulombic } \\
\text { Efficiency } \\
(\%)\end{array}$ & $\begin{array}{c}\text { Capacity Retention at } \\
\text { 100th Cycle } \\
(\%)\end{array}$ \\
\hline GeTe & 679 & 987 & 69 & 58 \\
\hline GeTe-TiC (10\%)-C & 655 & 778 & 84 & 98 \\
\hline GeTe-TiC (20\%)-C & 558 & 729 & 76 & 99 \\
\hline GeTe-TiC (30\%)-C & 508 & 722 & 70 & 99 \\
\hline
\end{tabular}

The CV test was conducted to further elucidate the electrochemical reactions. Figure 5 shows the initial cyclic voltammograms of GeTe and GeTe-TiC-C electrodes within a voltage range of 0-2.5 $\mathrm{V}$ at $0.1 \mathrm{mVs}^{-1}$. The potential plots of GeTe-TiC-C electrodes exhibit the analogous behavior. In the initial lithiation process, the reaction potentials from 1.9 to $0.9 \mathrm{~V}$ illustrated the alloy reactions of Te with $\mathrm{Li}$ ions to form the $\mathrm{Li}_{2} \mathrm{Te}$ phase $\left(\mathrm{GeTe}+2 \mathrm{Li}^{+} \rightarrow \mathrm{Li}_{2} \mathrm{Te}+\mathrm{Ge}\right)[35,51]$. In practice, the redox potential of Te strongly relied on morphologies and dispersing matrices $[54,55]$. Figure 5 a disclosed that the lithiation of Te occurred at 1.1 and $1.54 \mathrm{~V}$ in the first cycle for the as-prepared GeTe. In fact, stress-related factors frequently influenced the lithiation potential of the chalcogens [44]. Due to the stress caused by the TiC matrix after the embedding process, only one cathodic peak at $1.34 \mathrm{~V}$ was observed in the first cycle for the lithiation of Te in GeTe-TiC-C composites. From the second cycle, for all the composite electrodes, the relaxation of Te split the aforementioned cathodic peak (1.34 V) into two peaks at $1.1 \mathrm{~V}$ and $1.63 \mathrm{~V}$, which were identical to the lithiation potential of Te in the GeTe electrode (Figure 5). In addition, the cathodic peak at $1.96 \mathrm{~V}$ could correspond to an additional SEI formation, which occasionally happened in Te-based electrodes. For example, by embedding ultrafine Te particles in carbon matrices, Liu et al. observed an irreversible cathodic peak at $\approx 2 \mathrm{~V}$ for the 1 st cycle [50].
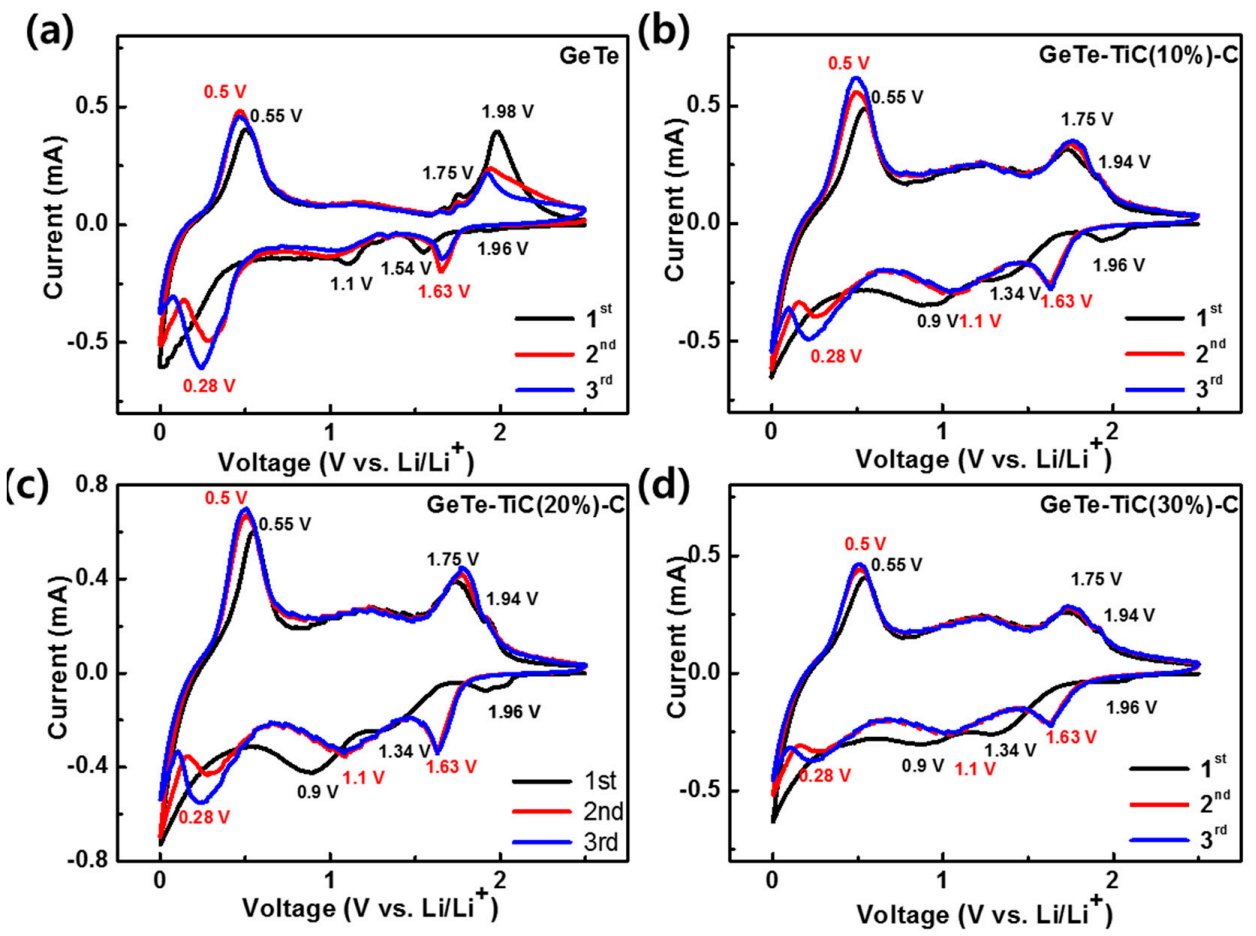

Figure 5. Cyclic voltammograms of (a) GeTe, (b) GeTe-TiC (10\%)-C, (c) GeTe-TiC (20\%)-C, and (d) GeTe-TiC (30\%)-C in the three initial cycles at $0.1 \mathrm{mV} \mathrm{s}^{-1}$.

Moreover, a broad peak was observed at approximately $0.25 \mathrm{~V}$ on further discharging to a lower voltage, which was ascribed to the formation of the $\mathrm{Li}_{3.75} \mathrm{Ge}$ phase along with the solid electrolyte interphase layer formation on the surface of the electrode material $\left(\mathrm{Ge}+3.75 \mathrm{Li}^{+} \rightarrow \mathrm{Li}_{3.75} \mathrm{Ge}\right)$. In 
2015, Ngo et al. suggested that the lithiation of Ge might reveal multiple cathodic peaks, whereas the SEI formation occurred right before the lowest lithiation potential of Ge during the discharging [56]. Accordingly, it is reasonable to attribute the broad cathodic peak at $0.25 \mathrm{~V}$ to an overlap of two reactions: a lithiation of Ge and SEI formation. Meanwhile, in the initial delithiation process, the sequential reversible reaction of $\mathrm{Li}_{3.75} \mathrm{Ge}$ to Ge occurred when the potential increased from 0.01 to 0.55 $\mathrm{V}\left(\mathrm{Li}_{3.75} \mathrm{Ge} \rightarrow \mathrm{Ge}+3.75 \mathrm{Li}^{+}\right)$[57]. In the further charged state, two oxidation peaks were observed at 1.75 and $1.98 \mathrm{~V}$ for GeTe, and 1.75 and $1.94 \mathrm{~V}$ for GeTe-TiC-C electrodes. Both reaction potentials were related to the dealloying reaction of the $\mathrm{Li}_{2} \mathrm{Te}$ phase $\left(\mathrm{Li}_{2} \mathrm{Te}+\mathrm{Ge} \rightarrow \mathrm{GeTe}+2 \mathrm{Li}^{+}\right)$. In the case of the GeTe electrode, it showed the main peak at $1.98 \mathrm{~V}$ with a weak shoulder peak at $1.75 \mathrm{~V}$. On the other hand, GeTe-TiC-C electrodes revealed the main peak at $1.75 \mathrm{~V}$ with a weak peak at $1.94 \mathrm{~V}$. This might be because the introduction of TiC-C into GeTe changed the main reaction potentials. In addition, the broad cathodic and anodic peaks at around $1 \mathrm{~V}$ were observed, which might be related to the alloying/dealloying reactions of $\mathrm{Te}$ and $\mathrm{Li}$ as well [35]. The large broadness of the peaks could be due to the gradual (de)alloying reactions; then, main reaction at a redox potential of 1.63/1.75 V occurred. After the first cycle, the reduction peaks are shifted toward a higher potential, while all the oxidation peaks were shifted slightly to a lower voltage, illustrating the reduced electrode polarization during the discharge-charge processes $[33,50,57]$. During the first discharge process, unstable and wide peaks were observed in all the electrodes, corresponding to the SEI layer formation. The peaks were stabilized from the second and third cycles for GeTe-TiC-C electrodes, which is a result of the reversible electrochemical reactions. The overall reaction mechanism can be summarized as follows.

In the discharge process:

$$
\mathrm{GeTe} \rightarrow \mathrm{Ge}+\mathrm{Li}_{2} \mathrm{Te} \rightarrow \mathrm{Li}_{3.75} \mathrm{Ge}+\mathrm{Li}_{2} \mathrm{Te}
$$

In the charge process:

$$
\mathrm{Li}_{3.75} \mathrm{Ge}+\mathrm{Li}_{2} \mathrm{Te} \rightarrow \mathrm{Ge}+\mathrm{Li}_{2} \mathrm{Te} \rightarrow \mathrm{GeTe} .
$$

The cyclic performances and the Coulombic efficiency of GeTe and GeTe-TiC-C electrodes at $100 \mathrm{~mA} \mathrm{~g}^{-1}$ are compared in Figure $6 \mathrm{a}$. The GeTe electrode has the highest initial discharge capacity (987 $\mathrm{mAh} \mathrm{g}^{-1}$ ); however, the capacity retention after 100 cycles was approximately $58 \%$ with respect to the value in the 2 nd cycle, which proves its rapid fading capacity. This implies that only GeTe was unable to endure the large volume expansion. The GeTe alloy possesses large volume expansion and critical aggregation issues during the cycling, which could lose the electrical contact with the binder/super P/current collector and cause the pulverization of the electrode $[33,35,36]$. In contrast, the cyclic performances were much improved by introducing the TiC-C buffering matrix into the GeTe alloy. The GeTe-TiC (10\%)-C electrode exhibits a better discharge capacity of $711.4 \mathrm{mAh} \mathrm{g}^{-1}$ than those of GeTe-TiC (20\%)-C and GeTe-TiC (30\%)-C after 100 cycles, resulting from the higher GeTe active material content in the composite compared to others. However, the capacity gradually decreases up to the 156th cycle. This could be attributed to the insufficient amount of TiC in the composite that could not sufficiently prevent the GeTe active particles from the volume expansion during repeated cycling. Composites with higher TiC weight percent, the GeTe-TiC (20\%)-C and GeTe-TiC (30\%)-C electrodes, displayed discharge capacities of 641.6 and $531.7 \mathrm{mAh} \mathrm{g}^{-1}$, respectively, after 100 cycles, which correspond to high capacity retentions of $\approx 99 \%$ with respect to the values in the 2nd discharge capacity. With a further increase in cycles, the electrodes showed a gradual increase in capacity, leading to over $100 \%$ capacity retention. The gradual increase in capacity upon long cycling may be attributed to the activation process triggered by the gradual wetting and soaking of the electrolyte into electrodes [33,58,59]. Most importantly, the changes in the capacity plateaus (Figure S1) after some cycles support the reversible establishment and degradation of polymer/gel-like film that serves as a reservoir for the storage of excess $\mathrm{Li}^{+}$ions via a pseudocapacitance-type behavior $[33,60]$. This could be owing to the electrolytes decomposition and the electrochemical catalytic effect of the formed nanoparticles (NPs) on accelerating or activating the decomposition of certain SEI [61]. 
The two electrodes with high TiC content $(20 \%$ and $30 \%)$, when conducting a long-lasting cyclic test, exhibited superior cyclic performance even after 400 cycles. When the TiC content was optimized to be $20 \mathrm{wt} \%$ (GeTe-TiC (20\%)-C), both high-capacity and cyclic stability were realized. In particular, it exhibited a capacity of $847.1 \mathrm{mAh} \mathrm{g}^{-1}$ after 400 cycles. This can be attributed to the introduction of an appropriate amount of $\mathrm{TiC}$ dispersed uniformly in the matrix, which effectively suppresses the aggregation of active GeTe, increases the conductivity of the entire matrix, reduces the particle size, and mitigates the stresses and strains during the extended cycling $[33,35,36]$. Moreover, the developed composites possess high tap densities of $2.4 \mathrm{~g} \mathrm{~cm}^{-3}$ for GeTe-TiC (20\%)-C and $2.3 \mathrm{~g} \mathrm{~cm}^{-3}$ for GeTe-TiC (30\%)-C. Based on these values, the volumetric capacity was obtained by multiplying the specific capacity and tap density. Figure $6 \mathrm{~b}$ shows the volumetric capacity of GeTe-TiC-C electrodes; for comparison, the theoretical volumetric capacity for graphite is plotted as a line. The GeTe-TiC (20\%)-C electrode demonstrated a volumetric capacity of $1657 \mathrm{mAh} \mathrm{cm}^{-1}$ after 200 cycles. Furthermore, the GeTe-TiC (30\%)-C electrode exhibited a volumetric capacity of $1281 \mathrm{mAh} \mathrm{cm}{ }^{-3}$ after the same number of cycles. The volumetric capacity values of GeTe-TiC-C electrodes are three or five times greater than the theoretical volumetric capacity of the graphite anode $\left(372 \mathrm{mAh} \mathrm{g}^{-1} \times 0.9 \mathrm{~g} \mathrm{~cm}^{-3}=\right.$ $335 \mathrm{mAh} \mathrm{cm}^{-3}$ ), indicating that the composite electrodes possess sufficient potential as an alternative. The measured tap density of graphite was consistent with that reported in other study [62]. Table S1 shows a comparison of the cyclic performance of electrodes with $\mathrm{TiC}$ content in composite materials. When comparing the developed electrodes with others, the GeTe-TiC-C electrodes demonstrated stable cyclability (Figure 6a,b) and high reversible capacity upon long lasting cycling, which are comparable to other electrodes. Interestingly, we found that the GeTe-TiC-C possessed a long activation time, which hardly happened for other telluride-based materials such as SnTe-TiC-C [35]. Moreover, GeTe-TiC-C composites were overall higher than SnTe-TiC-C composites in reversible capacity. Namely, after 400 cycles, our optimized composite electrode delivered a reversible gravimetric capacity $\left(847 \mathrm{mAh} \mathrm{g}^{-1}\right)$ that was twice that of SnTe-based electrode $\left(\approx 400 \mathrm{mAh} \mathrm{g}^{-1}\right)$.
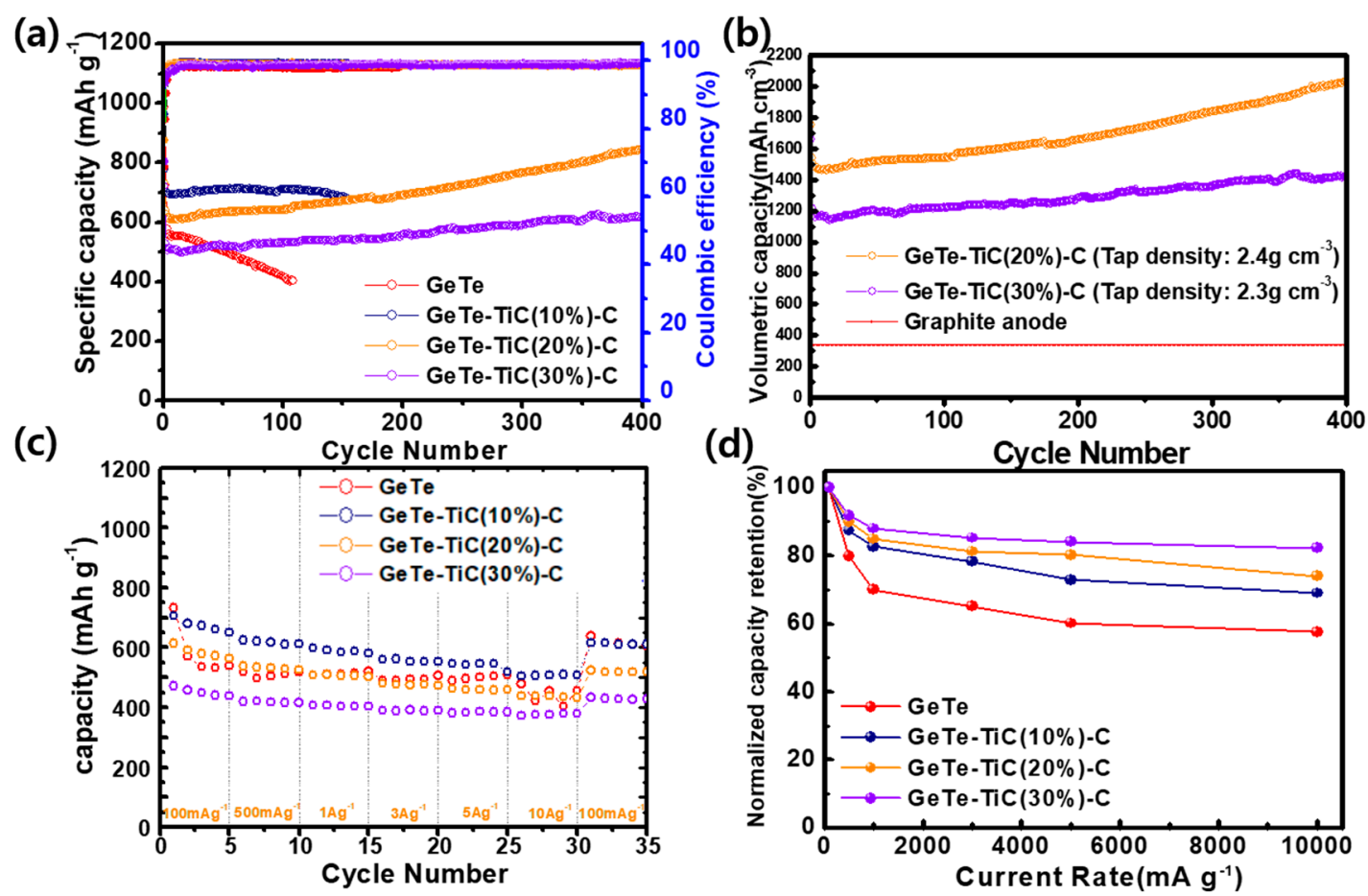

Figure 6. Cycling performance comparison of GeTe and GeTe-TiC-C anodes at $100 \mathrm{~mA} \mathrm{~g}^{-1}$ for (a) gravimetric capacity and (b) volumetric capacity. (c) Rate performance of GeTe and GeTe-TiC-C anodes at different current densities and (d) their capacity retentions. 
Fast charging with high efficiency has been required by industries in recent years. Figure $6 c, d$ display the results of the rate performance obtained by varying current densities from 0.1 to $10 \mathrm{~A}$ $\mathrm{g}^{-1}$. The GeTe electrode demonstrated an unstable rate performance, which is similar to the result of cyclability. The addition of TiC and $\mathrm{C}$ into composites improved the rate stability of the GeTe-TiC-C electrodes [52,53]. For instance, the charging capacity of the GeTe-TiC $(10 \%)-\mathrm{C}$ electrode at $10 \mathrm{~A} \mathrm{~g}^{-1}$ was $485 \mathrm{mAh} \mathrm{g}^{-1}$. It further displayed a slightly higher capacity retention (69\%) than the GeTe electrode (57\%). When the amount of TiC was applied as $20 \mathrm{wt} \%$ and $30 \mathrm{wt} \%$ in the composite, the GeTe-TiC (20\%)-C and GeTe-TiC (30\%)-C electrodes exhibited excellent rate capacity retention corresponding to $78 \%$ and $82 \%$, respectively. This notable rate performance of GeTe-TiC (20\%)-C and GeTe-TiC (30\%)-C can be ascribed to the coexistence of the hybrid TiC and $\mathrm{C}$ matrix, acting as a buffering agent with high conductivity and minimizing the large volume expansion during cycling.

EIS measurements were performed after 100 cycles to analyze the relationship between the cycling performance and resistance, as displayed in Figure 7. Nyquist plots were obtained from GeTe and GeTe-TiC (20\%)-C electrodes (Figure 7a), which includes semicircles in a high-frequency zone. A modified Randles circuit was selected as an equivalent circuit, which contains series resistance $\left(R_{s}\right)$, charge-transfer resistance $\left(\mathrm{R}_{\mathrm{ct}}\right)$, SEI resistance $\left(\mathrm{R}_{\mathrm{SEI}}\right)$, and a Warburg element $(\mathrm{W})$ (Figure $\left.7 \mathrm{~b}\right)$. To improve the simulation's goodness of fit, constant-phase elements (CPEs) were assigned to replace double-layer capacitors; the simulation results are summarized in Table 2. Even though the uncertainty in determining $R_{S}( \pm 1.0 \Omega)$ and $R_{S E I}( \pm 58.1 \Omega)$ was satisfactory, the simulated $R_{c t}$ was highly unreliable due to its tremendous uncertainty $( \pm 145 \mathrm{k} \Omega)$. The primary criterion in EIS fitting was minimizing the difference between an observed pattern and a simulated one. As the total impedance of the equivalent circuit consists of nine independent parameters, there could be many solution sets satisfying the primary criterion $[63,64]$. By varying parameters within their uncertainties, the simulated patterns were nearly identical. For instance, unless the values of $R_{c t}$ for the GeTe electrode exceeded 163 $\mathrm{k} \Omega$ (upper limit), the best goodness of fitting could still be mathematically achieved via varying other parameters such as capacitances or the Warburg coefficient. By applying further constraints or considering secondary criteria, we could reduce the statistical uncertainty and increase the physical meaning of the refined parameters. Therefore, the low-frequency constraint suggested by Vo et al. was applied to refine $R_{c t}[65]$. In Figure $7 c$ and d, the trend line of the sum of impedances $\left(Z_{\text {real }}+Z_{\text {imag }}\right)$ at low frequency had a negative slope and an X-intercept of $882 \Omega$, which are the sum of resistances $\left(R_{S}\right.$ $\left.+R_{S E I}+R_{c t}\right)$. Since the simulated values of both $R_{S}$ and $R_{S E I}$ were dependable, the value of $R_{c t}$ was estimated as $848 \Omega$ for the GeTe electrode. Similarly, in the case of the GeTe-TiC (20\%)-C electrode, the low-frequency constraint also proposed that the value of $R_{c t}$ could be $278 \Omega$. These results indicate that the introduction of TiC and C did not considerably influence the electrical conductivity of the SEI layers, as the values of $\mathrm{R}_{\mathrm{SEI}}$ for electrodes prepared from GeTe and GeTe-TiC (20\%)-C were nearly identical. Meanwhile, the overall $R_{c t}$ was reduced three times by introducing TiC-C (from $848 \Omega$ down to $278 \Omega$ ). In 2015, Allcorn and Mathiram also analyzed EIS spectra of FeSb-TiC-C composite electrodes and observed that all the composite electrodes initially had similar $R_{c t}$ regardless of TiC content [53]. However, the $\mathrm{R}_{\mathrm{ct}}$ values of the TiC-lesser electrodes drastically increased with cycling time, whereas those of the TiC-rich electrodes hardly changed. Since the charge-transfer kinetic strongly relied on the connectivity of the active phase, low $R_{\mathrm{ct}}$ was usually achieved for well-connected particles. As TiC alleviated the pulverization and supplied good connectivity, the $\mathrm{R}_{\mathrm{ct}}$ values of the TiC-rich electrodes hardly increased with cycling time. In contrast, without $\mathrm{TiC}$, the alloying-type electrodes usually suffered a great volume expansion and quickly lost their connectivity through operation [10]. Therefore, the $\mathrm{R}_{\mathrm{ct}}$ of the GeTe electrode dramatically increased through cycling. Accordingly, after 100 cycles, the GeTe-TiC (20 \%)-C electrode demonstrated much lower $R_{\mathrm{ct}}$ than the GeTe electrode because TiC-C well maintained the connectivity among GeTe particles. Having a small $\mathrm{R}_{\mathrm{ct}}$ and a negligible $\mathrm{R}_{\mathrm{SEI}}$ undoubtedly proved that the GeTe-TiC (20\%)-C electrode was suitable for fast charging application, which was consistent with the rate characterization (Figure $6 \mathrm{c}, \mathrm{d}$ ). Therefore, based on the 
cyclic performance and impedance results, it is evident that the GeTe-TiC-C electrodes are viable alloy anodes for high-performance LIBs.

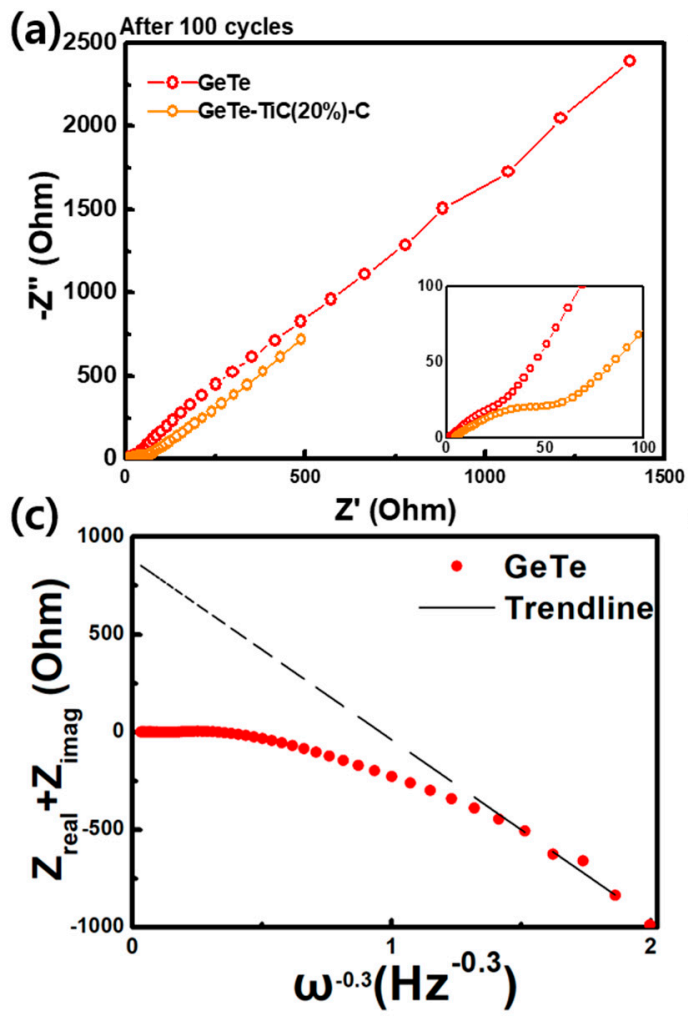

(b)
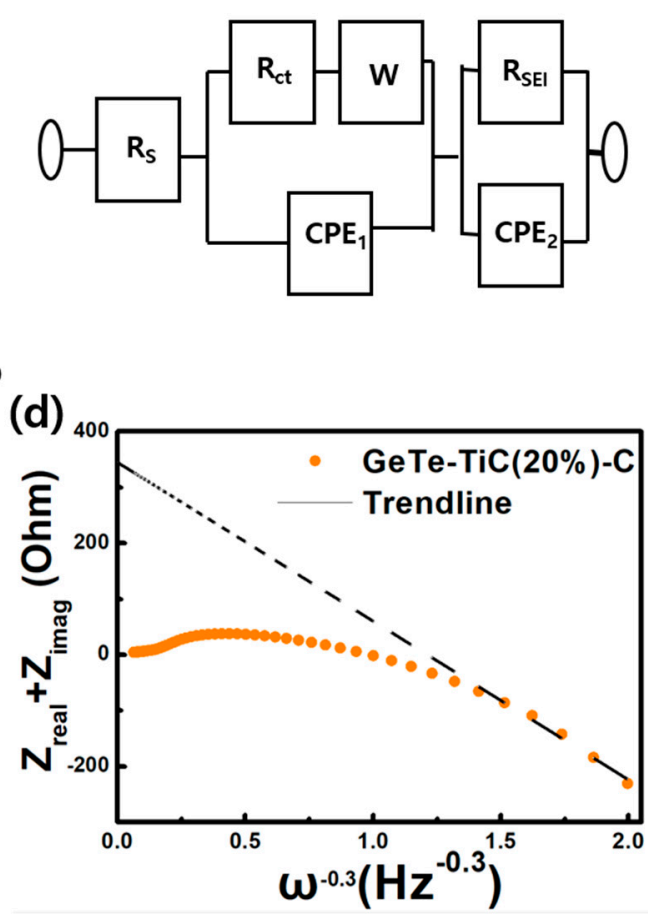

Figure 7. Nyquist plots for electrochemical impedance spectroscopy (EIS) spectra of GeTe and GeTe-TiC $(20 \%)$-C electrodes (a) after 100 cycles, with (b) the corresponding equivalent circuit. $\left(Z_{\text {real }}+Z_{\text {imag }}\right)$ plots of GeTe electrode (c) and GeTe-TiC (20\%)-C electrode (d).

Table 2. EIS data of GeTe and GeTe-TiC-C electrodes after 100 cycles without constraint verification.

\begin{tabular}{ccccc}
\hline Sample & $\begin{array}{c}\mathbf{R}_{\mathbf{s}} \\
(\boldsymbol{\Omega})\end{array}$ & $\begin{array}{c}\mathbf{R}_{\mathbf{c t}} \\
(\boldsymbol{\Omega})\end{array}$ & $\begin{array}{c}\mathbf{R}_{\text {SEI }} \\
(\boldsymbol{\Omega})\end{array}$ & $\boldsymbol{\alpha}$ \\
\hline GeTe & $1.5 \pm 1.0$ & $15,771 \pm 148,054$ & $32.3 \pm 58.1$ & 0.7 \\
GeTe-TiC $(20 \%)-C$ & $5.7 \pm 1.8$ & $618.3 \pm 19,590$ & $60.7 \pm 32.9$ & 0.7 \\
\hline
\end{tabular}

\section{Conclusions}

In this study, GeTe-TiC-C composites were synthesized via high-energy ball milling (HEBM). From the milled product, crystalline GeTe and TiC phases were dispersed in a carbon matrix. The prepared electrode displayed superior electrochemical performance compared with the GeTe electrode. GeTe displayed a low capacity retention of 58\% after 100 cycles, whereas GeTe-TiC-C electrodes exhibited exceedingly high capacity retentions. The TiC crystallites with high conductivity helped in mitigating large volume changes in the amorphous carbon matrix as the $\mathrm{TiC}$ content increased, ensuring outstanding cyclic life. Specifically, GeTe-TiC (20\%)-C and GeTe-TiC (30\%)-C electrodes displayed excellent volumetric and specific capacities, corresponding to $1657 \mathrm{mAh} \mathrm{cm}^{-3}$ and $690 \mathrm{mAh} \mathrm{g}^{-1}, 1281 \mathrm{mAh} \mathrm{cm}^{-3}$, and $557 \mathrm{mAh} \mathrm{g}^{-1}$, respectively, after 200 cycles. Moreover, at $10 \mathrm{~A} \mathrm{~g}^{-1}$, the GeTe-TiC (20\%)-C and GeTe-TiC (30\%)-C retained a high reversible capacity ( $78 \%-82 \%)$. Therefore, the outstanding electrochemical properties of the GeTe-TiC-C composite materials suggest a potential alternative to graphite for high-performance lithium-ion cells. 
Supplementary Materials: The following are available online at http://www.mdpi.com/1996-1944/13/19/4222/s1, Figure S1: Discharge-charge curves of (a) GeTe, (b) GeTe-TiC (20\%)-C and (c) GeTe-TiC (30\%)-C electrodes, Table S1: Comparison on the electrochemical performances of electrodes with TiC content. For other data, they are adapted from the cited references.

Author Contributions: W.S.K.: Conceptualization, Methodology, Validation, Visualization, Writing-review and editing. T.N.V.: Methodology, Visualization, Writing—review and editing. I.T.K.: Project administration, Funding acquisition, Review and editing. All authors have read and agreed to the published version of the manuscript.

Funding: This work was supported by the Korea Institute of Energy Technology Evaluation and Planning (KETEP) and the Ministry of Trade, Industry \& Energy (MOTIE) of the Republic of Korea (No. 20194030202290). This work was supported by the Gachon University research fund of 2019(GCU-2019-0806).

Conflicts of Interest: The authors declare no conflict of interest.

\section{References}

1. Arico, A.S.; Bruce, P.; Scrosati, B.; Tarascon, J.M.; Van Schalkwijk, W. Nanostructured materials for advanced energy conversion and storage devices. Nat. Mater. 2005, 4, 366-377. [CrossRef] [PubMed]

2. Mauger, A.; Julien, C.M.; Paolella, A.; Armand, M.; Zaghib, K. Building better batteries in the solid state: A review. Materials 2019, 12, 3892. [CrossRef] [PubMed]

3. Han, J.T.; Liu, D.Q.; Song, S.H.; Kim, Y.; Goodenough, J.B. Lithium ion intercalation performance of niobium oxides: $\mathrm{KNb}_{5} \mathrm{O}_{13}$ and $\mathrm{K}_{6} \mathrm{Nb}_{10.8} \mathrm{O}_{30}$. Chem. Mater. 2009, 21, 4753-4755. [CrossRef]

4. Abada, S.; Marlair, G.; Lecocq, A.; Petit, M.; Sauvant-Moynot, V.; Huet, F. Safety focused modeling of lithium-ion batteries: A review. J. Power Sources 2016, 306, 178-192. [CrossRef]

5. Aurbach, D.; Zinigrad, E.; Cohen, Y.; Teller, H. A short review of failure mechanisms of lithium metal and lithiated graphite anodes in liquid electrolyte solutions. Solid State Ion. 2002, 148, 405-416. [CrossRef]

6. McDowell, M.T.; Lee, S.W.; Nix, W.D.; Cui, Y. 25th anniversary article: Understanding the lithiation of silicon and other alloying anodes for lithium-ion batteries. Adv. Mater. 2013, 25, 4966-4984. [CrossRef]

7. Nguyen, Q.H.; Park, T.; Hur, J. Enhanced cycle stability of zinc sulfide anode for high-performance lithium-ion storage: Effect of conductive hybrid matrix on active ZnS. Nanomaterials 2019, 9, 1221. [CrossRef]

8. Nguyen, T.A.; Lee, S.W. Green synthesis of N-doped carbon modified iron oxides ( $\mathrm{N}-\mathrm{Fe}_{2} \mathrm{O}_{3} @$ Carbon) using sustainable gelatin cross-linker for high performance Li-ion batteries. Electrochim. Acta 2017, 248, 37-45. [CrossRef]

9. Zhang, L.; Rajagopalan, R.; Guo, H.P.; Hu, X.L.; Dou, S.X.; Liu, H.K. A green and facile way to prepare granadilla-like silicon-based anode materials for Li-Ion batteries. Adv. Funct. Mater. 2016, 26, 440-446. [CrossRef]

10. Zhang, W.J. A review of the electrochemical performance of alloy anodes for lithium-ion batteries. J. Power Sources 2011, 196, 13-24. [CrossRef]

11. Li, W.H.; Sun, X.L.; Yu, Y. Si-, Ge-, Sn-based anode materials for lithium-ion batteries: From structure design to electrochemical performance. Small Methods 2017, 1, 1600037. [CrossRef]

12. Zhang, W.J. Lithium insertion/extraction mechanism in alloy anodes for lithium-ion batteries. J. Power Sources 2011, 196, 877-885. [CrossRef]

13. Lv, H.L.; Qiu, S.; Lu, G.X.; Fu, Y.; Li, X.Y.; Hu, C.X.; Liu, J.R. Nanostructured antimony/carbon composite fibers as anode material for lithium-ion battery. Electrochim. Acta 2015, 151, 214-221. [CrossRef]

14. Kamali, A.R.; Fray, D.J. Tin-based materials as advanced anode materials for lithium ion batteries: A review. Rev. Adv. Mater. Sci. 2011, 27, 14-24.

15. Obrovac, M.N.; Chevrier, V.L. Alloy negative electrodes for Li-ion batteries. Chem. Rev. 2014, 114, 11444-11502. [CrossRef]

16. Liu, L.H.; Xie, F.; Lyu, J.; Zhao, T.K.; Li, T.H.; Choi, B.G. Tin-based anode materials with well-designed architectures for next-generation lithium-ion batteries. J. Power Sources 2016, 321, 11-35. [CrossRef]

17. Ji, L.W.; Lin, Z.; Alcoutlabi, M.; Zhang, X.W. Recent developments in nanostructured anode materials for rechargeable lithium-ion batteries. Energ. Environ. Sci. 2011, 4, 2682-2699. [CrossRef]

18. Cho, Y.J.; Im, H.S.; Kim, H.S.; Myung, Y.; Back, S.H.; Lim, Y.R.; Jung, C.S.; Jang, D.M.; Park, J.; Cha, E.H.; et al. Tetragonal phase germanium nanocrystals in lithium ion batteries. ACS Nano 2013, 7, 9075-9084. [CrossRef] 
19. Chan, C.K.; Zhang, X.F.; Cui, Y. High capacity Li ion battery anodes using Ge nanowires. Nano Lett. 2008, 8, 307-309. [CrossRef]

20. Song, G.; Cheong, J.Y.; Kim, C.; Luo, L.L.; Hwang, C.; Choi, S.; Ryu, J.; Kim, S.; Song, W.J.; Song, H.K.; et al. Atomic-scale combination of germanium-zinc nanofibers for structural and electrochemical evolution. Nat. Commun. 2019, 10, 2364. [CrossRef]

21. Fuller, C.S.; Severiens, J.C. Mobility of impurity ions in germanium and silicon. Phys. Rev. 1954, 96, 21-24. [CrossRef]

22. Cui, G.L.; Gu, L.; Zhi, L.J.; Kaskhedikar, N.; van Aken, P.A.; Mullen, K.; Maier, J. A germanium-carbon nanocomposite material for lithium batteries. Adv. Mater. 2008, 20, 3079-3083. [CrossRef]

23. Leibowitz, J.; Allcorn, E.; Manthiram, A. SnSb-TiC-C nanocomposite alloy anodes for lithium-ion batteries. J. Power Sources 2015, 279, 549-554. [CrossRef]

24. Allcorn, E.; Manthiram, A. NiSb- $\mathrm{Al}_{2} \mathrm{O}_{3}-\mathrm{C}$ nanocomposite anodes with long cycle life for Li-ion batteries. J. Phys. Chem. C 2014, 118, 811-822. [CrossRef]

25. Graetz, J.; Ahn, C.C.; Yazami, R.; Fultz, B. Nanocrystalline and thin film germanium electrodes with high lithium capacity and high rate capabilities. J. Electrochem. Soc. 2004, 151, A698-A702. [CrossRef]

26. Zhao, H.H.; Qi, W.; Li, X.; Zeng, H.; Wu, Y.; Xiang, J.W.; Zhang, S.G.; Li, B.; Huang, Y.H. SnSb/TiO $2 / C$ nanocomposite fabricated by high energy ball milling for high-performance lithium-ion batteries. RSC Adv. 2016, 6, 32462-32466. [CrossRef]

27. Hai, N.Q.; Kim, H.; Yoo, I.S.; Hur, J. Facile and scalable preparation of a $\mathrm{MoS}_{2} /$ Carbon nanotube nanocomposite anode for high-performance lithium-ion batteries: Effects of carbon nanotube content. J. Nanosci. Nanotechnol. 2019, 19, 1494-1499. [CrossRef]

28. Nguyen, T.A.; Kim, I.T.; Lee, S.W. Chitosan-tethered iron oxide composites as an antisintering porous structure for high-performance Li-ion battery anodes. J. Am. Ceram. Soc. 2016, 99, 2720-2728. [CrossRef]

29. Yun, S.; Lee, Y.C.; Park, H.S. Phase-controlled iron oxide nanobox deposited on hierarchically structured graphene networks for lithium ion storage and photocatalysis. Sci. Rep. 2016, 6, 19959. [CrossRef]

30. Lee, J.M.; Jung, H.; Hwa, Y.; Kim, H.; Im, D.; Doo, S.G.; Sohn, H.J. Improvement of electrochemical behavior of $\mathrm{Sn}_{2} \mathrm{Fe} / \mathrm{C}$ nanocomposite anode with $\mathrm{Al}_{2} \mathrm{O}_{3}$ addition for lithium-ion batteries. J. Power Sources 2010, 195, 5044-5048. [CrossRef]

31. Nguyen, T.P.; Delbari, S.A.; Azizian-Kalandaragh, Y.; Babapoor, A.; Le, Q.V.; Sabahi Namini, A.; Shokouhimehr, M.; Shahedi Asl, M. Characteristics of quadruplet Ti-Mo-TiB 2 -TiC composites prepared by spark plasma sintering. Ceram. Int. 2020, 46, 20885-20895. [CrossRef]

32. Nguyen, T.P.; Pazhouhanfar, Y.; Delbari, S.A.; Le, Q.V.; Shaddel, S.; Pazhouhanfar, M.; Sabahi Namini, A.; Shokouhimehr, M.; Shahedi Asl, M. Characterization of spark plasma sintered TiC ceramics reinforced with graphene nano-platelets. Ceram. Int. 2020, 46, 18742-18749. [CrossRef]

33. Nguyen, Q.H.; Nguyen, Q.H.; So, S.; Hur, J. Efficient TiC-C hybrid conductive matrix for ZnTe anode in Lithium-ion storage. Appl. Surf. Sci. 2020, 534, 147679. [CrossRef]

34. Kim, S.-O.; Manthiram, A. High-performance Zn-TiC-C nanocomposite alloy anode with exceptional cycle life for lithium-ion batteries. ACS Appl. Mater. Int. 2015, 7, 14801-14807. [CrossRef] [PubMed]

35. Son, S.Y.; Hur, J.; Kim, K.H.; Son, H.B.; Lee, S.G.; Kim, I.T. SnTe-TiC-C composites as high-performance anodes for Li-ion batteries. J. Power Sources 2017, 365, 372-379. [CrossRef]

36. Kim, H.; Kim, M.; Yoon, Y.H.; Nguyen, Q.H.; Kim, I.T.; Hur, J.; Lee, S.G. $\mathrm{Sb}_{2} \mathrm{Te}_{3}-\mathrm{TiC}-\mathrm{C}$ nanocomposites for the high-performance anode in lithium-ion batteries. Electrochim. Acta 2019, 293, 8-18. [CrossRef]

37. Leibowitz, J.; Allcorn, E.; Manthiram, A. FeSn 2 -TiC nanocomposite alloy anodes for lithium ion batteries. J. Power Sources 2015, 295, 125-130. [CrossRef]

38. Kim, H.; Kim, J.; Hur, J. Effects of various hybrid carbon matrices on the ZnSe composite anode for lithium-ion batteries. J. Nanosci. Nanotechnol. 2019, 19, 6630-6635. [CrossRef]

39. Park, C.M.; Park, J.H.; Yoon, S.G. Conduction properties and a long-term stability of the transparent capacitors. J Electrochem. Soc. 2010, 157, G258-G261. [CrossRef]

40. Ji, X.L.; Nazar, L.F. Advances in Li-S batteries. J. Mater. Chem. 2010, 20, 9821-9826. [CrossRef]

41. Yang, Y.; Zheng, G.Y.; Misra, S.; Nelson, J.; Toney, M.F.; Cui, Y. High-capacity micrometer-sized Li $2 \mathrm{~S}$ particles as cathode materials for advanced rechargeable lithium-ion batteries. J. Am. Chem. Soc. 2012, 134, 15387-15394. [CrossRef] [PubMed] 
42. Yang, Y.; Zheng, G.Y.; Cui, Y. Nanostructured sulfur cathodes. Chem. Soc. Rev. 2013, 42, 3018-3032. [CrossRef] [PubMed]

43. Lee, D.H.; Park, C.M. Tin selenides with layered crystal structures for Li-ion batteries: Interesting phase change mechanisms and outstanding electrochemical behaviors. ACS Appl. Mater. Int. 2017, 9, 15439-15448. [CrossRef]

44. Luo, C.; Xu, Y.H.; Zhu, Y.J.; Liu, Y.H.; Zheng, S.Y.; Liu, Y.; Langrock, A.; Wang, C.S. Selenium@mesoporous carbon composite with superior lithium and sodium storage capacity. ACS Nano 2013, 7, 8003-8010. [CrossRef] [PubMed]

45. He, J.R.; Chen, Y.F.; Lv, W.G.; Wen, K.C.; Xu, C.; Zhang, W.L.; Li, Y.R.; Qin, W.; He, W.D. From metal organic framework to $\mathrm{Li}_{2} \mathrm{~S} @ \mathrm{C} \mathrm{Co} \mathrm{N}$ nanoporous architecture: A high capacity cathode for lithium sulfur batteries. ACS Nano 2016, 10, 10981-10987. [CrossRef]

46. Zhang, J.; Yin, Y.X.; You, Y.; Yan, Y.; Guo, Y.G. A high-capacity Tellurium@Carbon anode material for lithium-ion batteries. Energy Technol. 2014, 2, 757-762. [CrossRef]

47. Zhang, J.; Yin, Y.X.; Guo, Y.G. High-capacity Te anode confined in microporous carbon for long-life Na-ion batteries. ACS Appl. Mater. Int. 2015, 7, 27838-27844. [CrossRef]

48. Seo, J.U.; Seong, G.K.; Park, C.M. Te/C nanocomposites for Li-Te secondary batteries. Sci. Rep. 2015, 5, 7969. [CrossRef]

49. Nam, K.H.; Park, C.M. Layered $\mathrm{Sb}_{2} \mathrm{Te}_{3}$ and its nanocomposite: A new and outstanding electrode material for superior rechargeable Li-ion batteries. J. Mater. Chem. A 2016, 4, 8562-8565. [CrossRef]

50. Liu, Y.; Wang, J.W.; Xu, Y.H.; Zhu, Y.J.; Bigio, D.; Wang, C.S. Lithium-tellurium batteries based on tellurium/porous carbon composite. J. Mater. Chem. A 2014, 2, 12201-12207. [CrossRef]

51. Seo, J.U.; Park, C.M. ZnTe and ZnTe/C nanocomposite: A new electrode material for high-performance rechargeable Li-ion batteries. J. Mater. Chem. A 2014, 2, 20075-20082. [CrossRef]

52. Yoon, S.; Manthiram, A. Nanoengineered Sn-TiC-C composite anode for lithium ion batteries. J. Mater. Chem. 2010, 20, 236-239. [CrossRef]

53. Allcorn, E.; Manthiram, A. High-rate, high-density FeSb-TiC-C nanocomposite anodes for lithium-ion batteries. J. Mater. Chem. A 2015, 3, 3891-3900. [CrossRef]

54. Xu, J.; Xin, S.; Liu, J.W.; Wang, J.L.; Lei, Y.; Yu, S.H. Elastic carbon nanotube aerogel meets tellurium nanowires: A binder- and collector-free electrode for Li-Te Batteries. Adv. Funct. Mater. 2016, 26, 3580-3588. [CrossRef]

55. Koketsu, T.; Paul, B.; Wu, C.; Kraehnert, R.; Huang, Y.H.; Strasser, P. A lithium-tellurium rechargeable battery with exceptional cycling stability. J. Appl. Electrochem. 2016, 46, 627-633. [CrossRef]

56. Ngo, D.T.; Le, H.T.T.; Kim, C.; Lee, J.Y.; Fisher, J.G.; Kim, I.D.; Park, C.J. Mass-scalable synthesis of 3D porous germanium-carbon composite particles as an ultra-high rate anode for lithium ion batteries. Energy Environ. Sci. 2015, 8, 3577-3588. [CrossRef]

57. Nam, K.-H.; Sung, G.-K.; Choi, J.-H.; Youn, J.-S.; Jeon, K.-J.; Park, C.-M. New high-energy-density GeTe-based anodes for Li-ion batteries. J. Mater. Chem. A 2019, 7, 3278-3288. [CrossRef]

58. Cao, K.; Jiao, L.; Liu, H.; Liu, Y.; Wang, Y.; Guo, Z.; Yuan, H. 3D hierarchical porous $\alpha-\mathrm{Fe}_{2} \mathrm{O}_{3}$ nanosheets for high-performance lithium-ion batteries. Adv. Energy Mater. 2015, 5, 1401421. [CrossRef]

59. Luo, J.; Xia, X.; Luo, Y.; Guan, C.; Liu, J.; Qi, X.; Ng, C.; Yu, T.; Zhang, H.; Fan, H. Rationally designed hierarchical $\mathrm{TiO}_{2} @ \mathrm{Fe}_{2} \mathrm{O}_{3}$ hollow nanostructures for improved lithium ion storage. Adv. Energy Mater. 2013, 3, 737-743. [CrossRef]

60. Zheng, Z.; Zao, Y.; Zhang, Q.; Cheng, Y.; Chen, H.; Zhang, K.; Wang, M.S.; Peng, D.L. Robust erythrocyte-like $\mathrm{Fe}_{2} \mathrm{O}_{3} @$ Carbon with yolk-shell structures as high-performance anode for lithium ion batteries. Chem. Eng. J. 2018, 347, 563. [CrossRef]

61. Zhang, L.; Zhao, K.; Luo, Y.; Dong, Y.; Xu, W.; Yan, M.; Ren, W.; Liang, Z.; Qu, L.; Mai, L. Acetylene black induced heterogeneous growth of macroporous $\mathrm{CoV}_{2} \mathrm{O}_{6}$ nanosheet for high-rate pseudocapacitive lithium-ion battery anode. ACS Appl. Mater. Inter. 2016, 8, 7139-7146. [CrossRef]

62. Kim, N.; Chae, S.; Ma, J.; Ko, M.; Cho, J. Fast-charging high-energy lithium-ion batteries via implantation of amorphous silicon nanolayer in edge-plane activated graphite anodes. Nat. Commun. 2017, 8, 812. [CrossRef] [PubMed]

63. Hawkins, D.M. The problem of overfitting. J. Chem. Inf. Comp. Sci. 2004, 44, 1-12. [CrossRef] [PubMed] 
64. Tsai, Y.-T.; Whitmore, D.H. Nonlinear least-squares analyses of complex impedance and admitance data for solid electrolytes. Solid State Ion. 1982, 7, 129-139. [CrossRef]

65. Vo, T.N.; Kim, D.S.; Mun, Y.S.; Lee, H.J.; Ahn, S.-k.; Kim, I.T. Fast charging sodium-ion batteries based on Te-P-C composites and insights to low-frequency limits of four common equivalent impedance circuits. Chem. Eng. J. 2020, 398, 125703. [CrossRef]

(). (1)

(C) 2020 by the authors. Licensee MDPI, Basel, Switzerland. This article is an open access article distributed under the terms and conditions of the Creative Commons Attribution (CC BY) license (http://creativecommons.org/licenses/by/4.0/). 